\title{
Ayni Llajta: el trabajo comunitario como fundamento del proceso de democratización en Bolivia
}

\author{
Ayni Llajta: Community Work as the Foundation of the Democratization \\ Process in Bolivia
}

Fecha de recepción: 21 de febrero de 2016

Fecha de aprobación: 20 de mayo de 2017

Cómo citar este artículo/ to reference this article

Prieto Ruiz, Omar. (2017). Ayni Llajta: el trabajo comunitario como fundamento del proceso de democratización en Bolivia. Derecho Y Realidad, 15(29): e9083. Recuperado de

https://revistas.uptc.edu.co/index.php/derecho_realidad/article/view/9083

Resumen: Bolivia experimenta desde hace más de tres décadas un proceso de apertura democrática, pero ese proceso no consiste en el fortalecimiento de las instituciones del Estado boliviano, ni en hacer más efectivos los mecanismos electorales, consiste, más bien, en cuestionar estructuralmente esa forma particular de comprender la política y de reducirla a las dinámicas estatales. El texto tiene como objetivo principal demostrar que más allá de un fortalecimiento institucional, los cambios en Bolivia responden a una apertura hacia otros sectores de la sociedad boliviana que habían sido marginados. Y que ese proceso de inclusión generó una transformación radical, que no tiene retroceso, porque incluyó la mirada y las formas de organización de quienes estaban siendo excluidos, porque le dio la palabra a nuevas cosmovisiones que han transformado la dinámica política en el país, en el momento de ponerle límite. Este proceso se caracteriza por la inclusión de principios éticos comunitarios que cuestionan el fundamento de la sociedad burguesa occidental.

Palabras clave: democratización, Estado, principios éticos, herencia cultural, movimientos sociales. 


\begin{abstract}
Bolivia has been experimenting for more than three decades a process of democratic openness, but this process does not consist in strengthening the institutions of the Bolivian State or in making more effective electoral mechanisms. Rather, it consists in structurally questioning that particular form of understanding politics and reducing it to state dynamics. The main objective of the paper is to demonstrate that, beyond institutional strengthening, the changes in Bolivia respond to an opening to other sectors of Bolivian society that had been marginalized. And that inclusion process generated a radical transformation, which has no setback, because it included the look and forms of organization of those who were being excluded, because it gave the floor to new worldviews that have transformed the political dynamics in the country, at the moment of limiting it. This process is characterized by the inclusion of community ethical principles that question the foundation of Western bourgeois society.
\end{abstract}

Keywords: democratization, State, ethical principles, cultural heritage, social movements. 


\section{Introducción}

El presente texto es el resultado de un encuentro, de una charla. Ambientado con las palabras de un entrañable amigo boliviano radicado en Bogotá, quien describe desde su perspectiva los principales cambios acontecidos en el hermano país a lo largo de más de tres décadas del proceso de democratización. Con la nostalgia propia que trae consigo la distancia, el breve relato que sirve como pretexto para este trabajo permite vislumbrar los elementos fundamentales que considero determinantes para pensar el largo camino que ha recorrido Bolivia hasta configurar un nuevo proyecto de país como el que expresa la nueva Constitución Política. Cambios que, desde las palabras y desde la mirada de un boliviano que siente latente su herencia ancestral quechua, pueden expresarse conceptualmente en los términos de un resurgir, del nuevo despertar de una identidad y de unas formas de vida y organización silenciadas, olvidadas y puestas al margen, mas nunca desaparecidas en la conciencia de muchos de aquellos muchos y muchas que se piensan a sí mismos desde esos esquemas mundo-vitales.

Numerosos son los elementos que han permitido este cambio, este proceso de empoderamiento y concienciación de los sectores históricamente marginados y silenciados. Complejo, diverso y plural es el entorno desde el cual deben pensarse los cambios estructurales que ha vivido Bolivia. A pesar de las enormes dificultades que ha afrontado, y las que le faltan por asumir, el proceso de movilización social que ha echado a andar implica un elemento decisivo: es el compromiso vital de grupos humanos que luchan intensamente por el reconocimiento de su diversidad. Pero, precisamente, este proceso político ha implicado la deconstrucción de las interpretaciones externas que se le han impuesto. Es necesario, para permitir la llegada de nuevas voces y de nuevas miradas, confrontar aquellas que se han establecido de manera hegemónica. Esto supone una discusión con una manera de entender la política y con una manera de entender la democracia. Pero resultado de esta discusión es el convencimiento de que no existe la política sin la inclusión de esas voces silenciadas.

Este trabajo no pretende abarcar la totalidad de problemas, sentidos y procesos que están inmersos en la transformación que está experimentando Bolivia. Esa es una tarea que desborda las capacidades del autor. El siguiente es más bien un esfuerzo personal por comprender, por desentrañar los fundamentos éticos y políticos que se esconden tras el caso boliviano. Un intento por descubrir esas formas ancestrales que, para la mirada misma del autor, son todavía desconocidas en su dimensión profunda. Precisamente por ese descubrimiento también este trabajo es, en muchos sentidos, un proceso de transformación personal que está experimentando el autor. Una deconstrucción de lo que hasta ahora ha entendido como política.

\section{La historia de Saturnino}

Saturnino Flores Llampa vino al mundo el día de la Chakana. Sí, el día de la Cruz del Sur, uno de los símbolos más potentes y representativos de la cosmovisión andina. Me cuenta que nació en "la región más curiosa que el planeta tiene": el Salar de Uyuni. Cerca de allí, en un pequeño pueblo llamado Calasaya, a 3600 metros sobre el nivel del mar, se desarrolló 
su infancia y cursó sus primeros años de estudio. Desde muy niño aprendió de su mamá la lengua de los abuelos, el quechua, y creció en medio de sus tradiciones ancestrales. Pero también en medio de muchas dificultades. Para esa época, principios de la década de los sesenta, la región de Uyuni se consolidaba como uno de los principales centros ferroviarios del país, además de ser un territorio muy rico en recursos minerales. Sin embargo, como suele ocurrir muy a menudo en otras muchas regiones de América Latina, la riqueza natural del territorio contrasta con el abandono y el atraso al que los distintos gobiernos someten a las comunidades locales. Existe, podría decirse así, una relación inversamente proporcional entre la riqueza natural y la pobreza material de las personas. Un contraste que, desafortunadamente, parece una característica propia de nuestra comarca del mundo, como la llama Eduardo Galeano. A pesar de contar con aparentes ventajas naturales y estratégicas, Calasaya solo tenía, para entonces, una pequeña escuela que no daba abasto para las necesidades y las aspiraciones académicas de Saturnino.

En ese contexto, y ante las dificultades para poder acceder a la educación superior en su lugar de origen, Saturnino llega a Colombia en el año de 1976 apoyado por una comunidad religiosa que le ofrece una beca para estudios superiores. Estando acá pudo descubrir, al comparar con el nivel académico de la universidad donde se formó, que en su región natal la educación no solo no era una prioridad para el Estado, sino que no tenía, en ese entonces, un nivel académico suficiente que le permitiera competir en igualdad de condiciones con los estudiantes colombianos. A pesar de esto, y tras un gran esfuerzo y una admirable dedicación, pudo salir adelante en sus propósitos y un nuevo mundo académico se abrió para él. Realizó estudios de filosofía, con lo cual, como suele ocurrir a todos aquellos que nos adentramos en el pensamiento occidental, paulatinamente fue dejando a un lado sus raíces y un único esquema para comprender el mundo fue tomando posesión, convirtiéndose en una actitud frente a la vida. El joven boliviano llegó a Colombia con una beca para estudiar y acá, ya profesional, decidió llevar a cabo su proyecto de vida en la educación. Pero había otro factor que incidiría notablemente y que le permitiría ir abriendo nuevas puertas: su pasión, talento y compromiso con la música andina. Complementando sus estudios con sus dotes artísticas, Saturnino fue encontrando un espacio en esa sociedad que lo había recibido y en la cual, a varios miles de kilómetros de distancia de su hogar natal, se iba convirtiendo lentamente en el Satur, en el amigo que hace parte de nosotros. Que es con nosotros.

Lo conocí en el año de 1991 cuando empecé mis estudios secundarios en el Colegio Mayor de San Bartolomé. Allí, en pleno centro histórico de Bogotá, en una de las esquinas de la Plaza de Bolívar, un joven y carismático profesor de música nos enseñó, con particular dedicación, la experiencia casi mística de la música andina. Lo recuerdo sonriente y amable todo el tiempo, acompañado casi siempre de su charango, de una quena o de su zampoña. Singular talento para ejecutar cada instrumento pero, más aun, para transmitirnos esos aires ancestrales que desde niños nos acercaron espiritualmente con el mundo de las comunidades andinas. Sin saber nada de ese complejo universo que en ese entonces era desconocido para nosotros, apenas mentado al margen en uno que otro texto escolar, Satur nos enseñó a sentir como propia esa atmósfera andina que lo había formado y con la cual mantenía un vínculo indisoluble a través de su música. Esta fue, siempre, la banda sonora de esa época de nuestras vidas, y él, su talentoso y querido artífice. 
Algunos años después de salir del colegio volví a tener contacto con él. Ya se dedicaba, en la misma institución, a la docencia en el área de filosofía; yo apenas empezaba a transitar ese camino. Así que nos encontramos en varias ocasiones en las cuales pedí su consejo profesional, y él acudió en mi auxilio para darme pistas de cómo podía afrontar mi nuevo rol como filósofo-docente. Pero, de nuevo, más allá del colegio, el vínculo pasaba por el filtro de la música. Desde hace años Satur había conformado su grupo: Wiphalas: cantos de libertad. Se presentan a menudo en distintas partes de la ciudad y muchos de sus exalumnos aprovechamos la oportunidad para escucharlo nuevamente. Con el tiempo dejó de ser mi profesor para convertirse en un amigo y colega de quien seguí aprendiendo muchas cosas.

Hace un par de meses nos volvimos a encontrar. Lo llamé esta vez para hacerle una entrevista. Entusiasmado por mis descubrimientos y las lecturas realizadas, lo busqué nuevamente en el viejo Colegio Mayor para indagar sobre su perspectiva del proceso que vive su país desde hace un tiempo. ¿Quién mejor que él para darme una opinión al respecto? Nunca le había preguntado lo que le pregunté esa vez y él mismo me confesó que hace mucho tiempo no pensaba en el tema que le propuse porque nunca, hasta ahora, le habían preguntado por ese pequeño detalle: Saturnino es boliviano. Saturnino es quechua. Después de una breve introducción en la que me contó una pequeña parte de su vida, hizo una reflexión sobre el proceso político que vive su país natal. A medida que iban fluyendo sus palabras, siempre en una profunda actitud reflexiva con los ojos cerrados, me dijo que, para él, más allá de todas las diversas circunstancias que han rodeado el proceso y de las inmensas dificultades que ha tenido que sortear - y que ha creado - el Gobierno de Evo Morales Ayma, lo que pasa en su país no es otra cosa que el despertar de una conciencia y de una cultura que permanecía dormida o, mejor, ocultada, olvidada, menospreciada. Para Satur, mi amigo boliviano, el proceso de Bolivia es fundamentalmente "el resurgir de las enseñanzas de los abuelos".

Más allá de los términos políticos con los cuales uno trata de explicarlo, de pensarlo desde afuera, la transformación progresiva que vive el país andino tiene como núcleo central el redescubrimiento de unas raíces culturales y de unas formas de vivir en comunidad que habían sido puestas al margen tras el proceso de colonización estructural y sistemática padecido por este y los demás países de la región. Es una nueva forma de conciencia que han adquirido los movimientos sociales y los diversos sujetos populares y campesinos sobre sí mismos, sobre sus propias características, capacidades, potencialidades y, sobre todo, la valoración positiva de esa identidad que se descubre como igualmente válida y merece una oportunidad para expresarse en el espacio público de la vida política. Una nueva conciencia que, al ir emergiendo y consolidándose, va cuestionando las estructuras políticas, sociales y económicas que la mantenían oculta. Pero el surgimiento de esa conciencia ancestral no es solamente la valoración positiva de unas subjetividades, sino, como consecuencia de lo anterior, la posibilidad de plantear nuevas relaciones intersubjetivas y con la naturaleza: una nueva forma de relacionarse entre sí y con la Madre Tierra, la Pachamama, que implican una visión de armonía y respeto como fundamento de la relación social.

Esta sentida intervención contrastaba fuertemente con un reproche que se hacía al final de la misma: "hace mucho tiempo no pensaba en esto, y no había caído en la cuenta, hasta que 
me lo preguntaste — refiriéndose a mi entrevista - de que he ido olvidando el legado de los abuelos. Yo mismo me siento dominado por esa cultura occidental que ha despreciado el legado de los abuelos; por la misma filosofía que estudié y que usa el criterio de un racionalismo estratégico que enseña otra manera de pensar y vivir el mundo en función de la utilidad que uno pueda obtener de los demás, o del medio ambiente. Tengo que reaprender y retomar mi quechua; tengo que volver a hablar mi quechua después de mucho tiempo en el que nos enseñaron a sentir vergüenza de nuestro quechua". Entonces, a pesar de reconocer en sí mismo esa identidad cultural, lo que hermosamente llama "el legado de los abuelos", Satur admite, al final de la entrevista, que ese despertar que lleva gestándose mucho tiempo en su pueblo, en él, como persona individual, hasta ahora empieza a concebirse como necesario. "Este despertar que hay en Bolivia para mí es muy reciente. En los tiempos de mi estudio, cuando nos conocimos, no tenía esta conciencia, no la había recuperado". Porque, en realidad, el proceso de concienciación sobre sus raíces, sobre la herencia de los abuelos o, mejor, el redescubrirse a sí mismo como indígena boliviano, ha implicado un cuestionamiento a esas estructuras rígidas y cerradas de pensamiento sobre las cuales se educó, y que simplifican la diversidad de formas de vida a solo una de sus manifestaciones históricas.

Pues bien, ese proceso de concienciación, de redescubrimiento de sí mismo en cuanto indígena boliviano es también, a gran escala, el proceso que se ha llevado a cabo desde la pluralidad constitutiva del pueblo boliviano y ha representado salir de la condición de subordinación histórica en todos los terrenos — cultural, político y social一, emergiendo como una fuerza política, como un bloque social que interpela desde afuera al establecimiento político-estatal y plantea alternativas diferentes de solución política que permitan la inclusión de esas diversas miradas que habían sido deliberadamente excluidas del proceso de formación del Estado y la sociedad bolivianos. Pero, ¿de qué es un despertar?, ¿con respecto a qué esa nueva conciencia representa un renacer, un redescubrir las raíces culturales? Por supuesto que la respuesta apunta a una única dirección: es la aparición de un bloque social plural que se ha consolidado a lo largo de diversos procesos de movilización y resistencia; de una nueva fuerza que entra a enfrentar la hegemonía política de una forma de organización estatal y, por lo tanto, institucional. Una hegemonía excluyente, clasista y racista que dominó durante siglos a Bolivia y que desde hace un tiempo se ve confrontada por una nueva alternativa de poder. Este proceso, del cual Saturnino es un reflejo individual, demuestra que para comprender el camino hacia la democratización política y social que se viene gestando en Bolivia tenemos que cuestionar los fundamentos y principios de ese poder excluyente que hizo del Estado una realidad ajena y externa a las bases populares trabajadoras, campesinas e indígenas. Y también al tipo de régimen político que lo justificó y lo legitimó, al menos desde los últimos 35 años: una cierta idea de la democracia como método, como procedimiento de reproducción estatal desde las lógicas de dominación del propio Estado.

Este proceso de reforma del sentido común reactiva y rearticula la memoria histórica, en particular de los hechos y procesos en los que a partir de la presencia popular se reformaron los Estados y se democratizaron los países en procesos de construcción nacional, como la revolución nacional del 52, la nacionalización y el cogobierno de partido nacionalista y obreros. Lo peculiar del proceso boliviano es que las fuerzas que hoy están articulando un nuevo sentido común y un nuevo 
bloque histórico son sujetos agrarios, algunos modernos, otros de matriz comunitaria. El horizonte nacional, que es el horizonte de articulación del sentido común, es un proceso que en principio está configurado por fuerzas agrarias. El proyecto nacional tiene una centralidad agraria en términos de los cuerpos sociales que lo sostienen y proyectan, aunque su horizonte es moderno. Por ejemplo, en Bolivia, el núcleo del proyecto es nacionalización e industrialización. Esta compleja composición produce tensiones que todavía están por desplegarse en el tiempo venidero. (Tapia, 2008b, p. 112)

Lo que viene en adelante es un esfuerzo por conceptualizar a partir de las palabras de Saturnino. Pero, sobre todo, de explicar en qué consiste esa particular ruptura, esa nueva conciencia que emerge y desde la cual es posible dar razones suficientes del porqué ese proceso de democratización implica, necesariamente, la inclusión de ese bloque social que se está convirtiendo en un bloque histórico de poder al reclamar el reconocimiento y la legitimidad de sus formas de vida y organización en el terreno político. Y cómo este proceso implica, necesariamente, una forma de descolonización. El resurgir de un nuevo sujeto político que, al romper la hegemonía que lo subordinaba y lo hacía invisible, confronta el establecimiento en una correlación de fuerzas que permiten, en esa tensión, la aparición de la política. Porque no se puede hablar de política cuando solo una facción de la sociedad impone sus criterios sobre las demás. Porque no es posible hablar de política cuando el poder se convierte en dominación, en imposición de una única perspectiva unilateral. La lucha conjunta y mancomunada de diversos sectores sociales contra esa dominación estructural, en diversos sentidos y momentos históricos, es lo que permite la comprensión de ese proceso, de esa dinámica emancipadora que hemos de llamar democratización: el movimiento de los movimientos sociales, verdaderos sujetos de la acción política en las últimas décadas en Bolivia. Protagonistas, desde su diversidad, del derrumbe de una sociedad históricamente jerarquizada y excluyente que, por esas dos razones, no puede llamarse a sí misma democrática.

Desarrollaré mi exposición en dos momentos complementarios y secuenciales. En el primero de ellos haré una muy breve descripción del carácter primigenio del poder estatal que echa sus raíces en los principios fundacionales de la modernidad. Sostendré la tesis de que ese proceso de subjetividad radical que se desarrolla en Europa, y que tiene a la burguesía como protagonista principal, jugó en América Latina, desde el inicio de la conquista, el papel de lo que Kant llama un "tutor"1. Esto es, la figura que representa el control sobre el pensamiento y la vida de aquel que es sometido a unas formas y dinámicas

\footnotetext{
${ }^{1}$ Tengo perfectamente claro que, en el texto de Kant, el tutor no es la causa de la llamada "minoría de edad". Que esta es, más bien, generada por la pereza y la cobardía para servirse del propio entendimiento con independencia. Si se interpreta literalmente mi referencia al texto de Kant, podría parecer que admito la vieja tesis colonialista según la cual las comunidades originarias de América del Sur son, frente al pensamiento europeo, incapaces de conducirse por sí mismas, ya que, carentes de pensamiento autónomo, requieren de la mano civilizadora del hombre blanco. No es este el sentido que quiero dar al término. Lo que quiero decir es que el pensamiento occidental, precisamente por no reconocer y por subvalorar las formaciones prehispánicas, pretende establecerse como un tutor. Se adjudica el derecho de reducir la diversidad de la vida a sus propios esquemas, al desconocer otras formas de pensamiento.
} 
que le son ajenas y de las que no participa activamente. Que el proceso de conquista y colonización fue, por encima de todo, un esfuerzo por hacer del colonizado una proyección de la imagen del colonizador (Memmi, 1966). En un segundo momento, derivado del primero, trataré de exponer que ese proceso que he llamado de democratización es el resultado de dos factores complementarios y simultáneos: primero, del proceso de organización colectiva y de confrontación al Estado que vino de la mano con los movimientos sociales, desde formas de organización política no estatal que es a lo que el profesor Luis Tapia llama el subsuelo político. Pero, segundo, esos movimientos sociales, esa pluralidad de formas de vida que convergen en una unidad de sentido, en un único proyecto político, traen consigo una visión alternativa de la vida social. Es más, su verdadera propuesta alternativa ante el poder político sustentado en el modelo neoliberal, consiste en rescatar el elemento social, a saber, de construcción colectiva de espacios comunes en función, no del beneficio individual y la competencia egoísta que caracteriza al mercado, sino de un espacio de relaciones comunitarias sustentadas en principios éticos.

El cambio profundamente revolucionario inmerso en el proceso de democratización consiste en la incorporación de principios normativos fundacionales que van a regir la dinámica política. Esta inclusión del elemento comunitario social — de principios éticos que deben regir la acción del Estado_-, descrito en las propias palabras de las personas más humildes, es el núcleo central del cambio que ha vivido el país hermano. Esa incorporación de nuevas visiones sobre el hombre y la naturaleza, alejadas de las pretensiones de dominio y control que caracterizan al pensamiento occidental, es de paso el elemento central de la dinámica de descolonización que atraviesa, con muchas dificultades, la sociedad boliviana.

Los verdaderos efectos de esa confrontación, de esa alternativa de organización, no se traducen en la reproducción de los ideales de vida burguesa que soportan el Estado moderno, sino todo lo contrario: en el posicionamiento en el discurso político de esas formas de vida comunitaria, ancestral, que Saturnino expresa bellamente como las enseñanzas de los abuelos. Ese proceso de movilización que ha confrontado el establecimiento político propone una alternativa al modo de producción capitalista, al colocar como fundamento del orden político unos principios éticos de respeto por la diversidad, por la naturaleza y una nueva dinámica social que reconoce los valores comunitarios. Porque ese proceso de movilización, proceso tras el cual se ha rescatado una identidad cultural, no culmina con la llegada al gobierno del Estado. Implica, necesariamente, una reforma profunda del mismo, que tiene como finalidad un nuevo proyecto de sociedad. "Para gobernar un país se necesita articular una concepción del mundo y de la época. Se necesita articular, también, un proyecto" (Tapia, 2008b, p. 106). Sin este elemento - expresado en los fundamentos de la Constitución del Estado Plurinacional-, ese proceso no dejará de ser una situación coyuntural y anecdótica que no confronta ni sustituye los viejos bloques de poder. Porque es en esto, en la correlación de fuerzas, en lo que consiste el Estado. De lo contrario, estático y cerrado en sí mismo, la política no es más que dominación disfrazada tras dinámicas electorales. Y esa lucha contra la dominación, tarea principal del pensamiento crítico, no es el resultado de esfuerzos individuales o aislados: es Ayni Llajta ${ }^{2}$, el trabajo de la comunidad.

\footnotetext{
${ }^{2}$ Todos los términos que empleo en quechua son sugerencias de Saturnino.
} 


\section{Fundamentación de la dinámica estatal moderna}

Mucha razón tenía Martin Heidegger al definir la modernidad como la época de la imagen del mundo. Con esto no se refería solo a los impresionantes alcances que, en el terreno práctico, tuvo el conocimiento humano convertido en ciencia. Si bien es cierto que esa renovada capacidad humana para comprender y dotar de sentido a la realidad representó un progreso cualitativo sin precedentes en la historia occidental, avance que encumbró al hombre y le concedió el lugar hasta antes asignado a las divinidades, esa misma capacidad de comprender y crear el mundo bajo sus esquemas de pensamiento es una forma de tomar posesión de la realidad y diseñarla conforme a sus intereses mundo-vitales. En tanto conciencia referida, esto es, en constante comparación con el pasado, la moderna mentalidad burguesa descubrió la potencialidad de la razón humana para crear un mundo a su imagen y semejanza.

Un mundo que, despojado de entelequias, de fuerzas intrínsecas y potencias creadoras, quedó a merced del proceso secular de racionalización que lo convirtió, como anunciaba el filósofo alemán, en un objeto de conocimiento que no existe en sí mismo sino en tanto pueda ser pensado y esquematizado por la razón calculante recién descubierta. Pero las implicaciones de esa nueva subjetividad trascienden los límites del ámbito epistemológico. Esa voluntad de poder, capacidad de dominio y transformación del mundo natural, permitió realizar el proyecto descrito por Descartes cuando advertía, en la sexta parte del Discurso del Método, que este avance epistémico permitiría al hombre convertirse "en una especie de dueño y poseedor de la naturaleza". Y esta, desnaturalizada y desprovista de cualidades inmanentes, quedó reducida a simple materia prima: a objeto cognoscible, sí, pero del que se puede sacar provecho para la satisfacción de los intereses materiales tras los procesos económico-políticos adyacentes a la voluntad de poder.

En esa nueva época de la imagen del mundo o, en otras palabras, del mundo convertido en objeto de pensamiento y apropiación material del hombre, el conocimiento no solo es visto como una aptitud creadora, dadora de sentido, sino como una capacidad abstracta: se concibe como descorporeizado y descontextualizado. Un conocimiento muy particular que pretende ser des-subjetivado, es decir, objetivo y universal y que, además, tiene pretensiones de verdad universal y de dominio natural — como si estos fueran fines en sí mismos-, pero despreocupado por las implicaciones éticas y las consecuencias que pueda generar. Esa razón instrumental universal no tiene lugar o cuerpo, ni tampoco género, raza o color. Eso le es indiferente en tanto pueda reducir toda la realidad a esquemas de pensamiento lógico. Esa racionalidad calculante, anclada en una conciencia renovada de lo humano y sus propias potencialidades e intereses, se consolidó como el centro mismo de la cultura moderna y configuró desde sí todas las dinámicas de la vida personal, social y política. Esa imagen del mundo mentada por Heidegger no describe una mera capacidad de recepción pasiva, o de esquematización conceptual. Todo lo contrario. A partir de esa esquematización, de esa cualidad para construir el sentido de todo lo real desde sí, la conciencia moderna redujo todo ámbito posible a sus propios esquemas. Se adjudicó, tras lo anterior, la potestad para determinar qué puede ser pensado, de qué forma es posible 
pensarlo, y cómo se debe adelantar el proceso. Redujo a sus criterios de pensamiento toda experiencia posible, convirtiéndose en esquema referencial para juzgar algo como racional, como cognoscible. Esa imagen del mundo anunciada por Heidegger, conciencia de las capacidades y alcances del hombre cuando se comprende a sí mismo desde su subjetividad como racionalidad creadora, no puede ser interpretada simplemente como una declaración optimista de un nuevo modo de entender el lugar que ocupa el hombre en la realidad, y de cómo va comprendiéndola sistemática y metódicamente para poder servirse de ella.

Este proceso brevemente descrito no se realizó en el vacío, ni se gestó espontáneamente; no es un proceso desvinculado de las dinámicas políticas y sociales que lo permitieron. No es este el momento ni el espacio apropiado para reconstruir el complejo proceso histórico que permitió a la burguesía tomar el lugar protagónico en la cultura occidental. No es ese el objetivo que persiguen estas líneas. Basta con aclarar que ese proceso de creación del mundo desde esquemas racionales, que esa manera de conquistar la realidad desde la subjetividad, tuvo profundas implicaciones en los ámbitos ético-políticos y económicos.

Así pues, a grandes rasgos, el pensamiento moderno no crea solamente la ciencia y sus consecuentes resultados en el campo del dominio natural, sino un modelo de organización social y un modo de producción que se cimentan, al menos en su fundamentación teórica, en los mismos principios que crean la ciencia. El Estado y el capitalismo son, también, resultado de esa voluntad de poder ejercida ya no sobre la naturaleza, sino sobre otras culturas y otros modos de pensar. Las manifestaciones más representativas de la modernidad antes descritas, podemos decir con sobradas razones, tienen la cualidad de presentarse como tendencias impositivas; emergen como procesos revolucionarios contra un estado de cosas precedente $\mathrm{y}$, consolidadas, van expandiéndose a medida que su desarrollo se hace consecuente. Esa imagen del mundo es, por encima de todo, una toma de posesión del mundo. Un proceso de colonización de todo lo existente, dinámica permanente que no se ve truncada por los límites que imponen sus propias fronteras. Una conquista del sentido pleno de toda la realidad. Uso este último término, conquista, para referirme al proceso sistemático de asimilación y apropiación simbólica que ejerce una comunidad o un individuo sobre otros: conquistar a otro es convertirlo a imagen y semejanza de mí mismo, eliminando los rasgos específicos que lo caracterizan como un otro diferente de mi propio yo, resignificando y revalorando su existencia en la medida en que refleja la mía: en que logro convertirlo en una proyección de mí mismo o de mi ideal. Pues bien, la tendencia del pensamiento moderno burgués, amparado en una definición específica del conocimiento, es a ampliarse y a tomar posesión de otras formas diferentes de pensamiento, justificado en esa imagen del mundo que va construyendo tras de sí.

Precisamente por lo anterior, el discurso de la modernidad tiene pretensiones universales y se expande hacia otras latitudes configurándolas a su imagen y semejanza. Crea la necesidad - tras las dinámicas de la economía-política y el saber científico - a todas las culturas pertenecientes a todas las regiones del mundo, de adherirse tanto a la epistemología moderna como al modo de organización y producción político y social; es decir, a aceptar que el modelo occidental es el único modelo válido para el conocimiento en el campo del saber, así como la doctrina del progreso y el Estado son el único modelo válido en el campo del poder (Lander, 2000). Y lo es precisamente por la manera como se ha definido académica y políticamente la modernidad: su capacidad de presentar su propia narrativa 
histórica como el único conocimiento válido posible, objetivo, científico y universal y, por supuesto, su visión de la sociedad moderna como la forma más avanzada de la existencia humana. Por ello con mucha agudeza Marx y Engels denuncian, en el Manifiesto del Partido Comunista, que la verdadera tarea de la burguesía es construirse un mundo a su imagen y semejanza. Y al hacerlo, por supuesto, no solo convierte sus visiones del mundo en categorías universales para la comprensión de cualquier realidad, sino que también las vuelve, indistintamente, proposiciones normativas que definen cómo debe ser un conocimiento, una sociedad, una economía, un ser humano, etc.

Esta colonización de la realidad por los intereses burgueses, como se ha dicho, se expresa en principio en esa particular imposición de una concepción del mundo que desconoce y niega otras formas diferentes de comprensión y de relación con la naturaleza. Pero esa colonialidad típica del pensamiento burgués no se limita solo a un punto de vista epistemológico, filosófico si lo podemos llamar de esta manera. Tiene que ver también, como lo expresa Félix Patzi, con un punto de vista sociológico. Con esto se refiere a un tipo de clasificación social a partir del criterio de raza, de etnia (Tapia, 2008, p. 83). A la manera como se impone una única imagen del hombre; un ideal de ser humano que prima por sobre la diversidad de manifestaciones culturales e históricas. Por ello el pensamiento burgués no solo crea una imagen del mundo, sino una imagen del hombre y de la relación social.

La expresión más potente de la eficacia del pensamiento científico moderno [...] es lo que puede ser descrito literalmente como la naturalización de las relaciones sociales, la noción de acuerdo a la cual las características de la sociedad llamada moderna son la expresión de las tendencias espontáneas, naturales del desarrollo histórico de la sociedad. La sociedad liberal industrial se constituye - desde esta perspectiva - no sólo en el orden social deseable, sino en el único posible. (Lander, 2000, p. 11.)

A estos ideales de la modernidad convertidos en el modelo arquetípico del hombre exitoso que habita en el mercado y que triunfa gracias a la posesión de conocimientos y saberes prácticos, es a lo que Herbert Marcuse llama precisamente, el hombre unidimensional. Esta es la concepción según la cual nos encontramos hoy en día en el punto máximo de realización de la sociedad, una sin ideologías, limpia de reclamaciones anacrónicas; un modelo de hombre y de cultura único, globalizado, universal, que hace innecesaria la discusión política, en la medida en que ya no hay alternativas posibles a ese modo de vida; que desprecia cualquier cuestionamiento por considerarlo irracional, o mal intencionado. En tanto sistema-mundo, es decir, en tanto representación total de lo existente, la sociedad burguesa apuesta todas sus cartas a perpetuarse indefinidamente; a diseñar a imagen y semejanza de sus necesidades toda la realidad (Borón, 2000). Pero la tendencia de la sociedad burguesa no se limita a imponer un pensamiento único, sino que busca, en la medida que sea posible, restringir la aparición de la conciencia crítica. El truco del sistema es presentarse como el mejor de los mundos posibles, muy a pesar de que la evidencia inmediata demuestra que sus consecuencias atentan directamente contra el ser humano y contra la naturaleza. ¿No es esta pretensión un intento por naturalizar un determinado modo 
de producción, de organización y de pensamiento?, ¿y este intento por eternizar el orden imperante de la relación social no implica necesariamente el fin del pensamiento, el fin de la política?

Esa imposición acrítica de los valores de la modernidad y su expansión hacia otras fronteras políticas y culturales fue la forma que adquirió el colonialismo en América Latina. Al menos, su lado más "amable". Una forma particular de imposición epistemológica, normativa y política que ha convertido las expresiones culturales no occidentales en un campo de prueba y expansión de los ideales triunfantes antes mencionados. Es de cara a la fuerza hegemónica y totalizante del pensamiento y de la tradición occidental, que la posibilidad de inscribir nuevas concepciones sobre el mundo, nuevas formas de ser y estar en él que vienen de la mano con la dinámica intercultural, con las tradiciones de los pueblos originarios, se hacen tan difíciles y llenas de complejos problemas. Y esto es así no solamente por la tendencia hegemónica y colonialista de occidente, sino por otros dos factores que inciden de manera determinante: primero, que esa visión unidimensional del hombre, del conocimiento y de la política, se acompaña de una narrativa histórica que los va relatando, que los justifica pero, sobre todo, de una comprensión del proceso histórico que excluye a buena parte de las personas que no están representadas en esta forma de comprender el proceso. Es decir, que esa tendencia homogeneizante también construye, a su acomodo, la historia; que hay una historia oficial. Sumado a esta invisibilización progresiva y sistemática de inmensos grupos de personas que no aparecen siquiera mencionados en la historia, se encuentra su consecuente desaparición en todos los terrenos de la cultura y, sobre todo, de la política. No comprenderlos como sujetos históricos es la primera forma de despolitización. Y estas dos son, a su vez, las condiciones de posibilidad de la sumisión que requiere el colonialismo.

Me explico: el problema fundamental con esa "herencia occidental" - herencia por demás no pedida ni aceptada voluntariamente por los pueblos de América Latina, sino impuesta de manera violenta y agresiva-, no consiste solo en la imposición de una forma de pensar y de organizar la sociedad, sino en la manera en la cual, para la historia, solo interviene un grupo selecto de personas que la crean y la sustentan. Es esa vieja tesis expuesta, entre otros, por el historiador francés Fernand Braudel para quien la historia no es otra cosa diferente a un "discurso de acontecimientos y héroes" (Braudel, 1993, pp. 35-36). Si la historia es ese relato de las acciones de hombres ilustres, en momentos específicos del tiempo, buena parte de las personas que intervienen en los procesos de transformación son deliberadamente olvidados al momento en que el historiador coloca su atención en aquellos que, desde el poder, recrean el proceso histórico desde su perspectiva particular ${ }^{3}$. Esa manera de concebir la historia excluye los procesos de resistencia y movilización de

\footnotetext{
${ }^{3}$ Este discurso histórico de los vencedores, de quienes tienen el poder, es lo que permite a Walter Benjamin criticar el papel de lo que llama "historiador historicista": de aquel para quien el proceso histórico no es más que un relato de los vencedores, dejando por fuera a los vencidos. Esa manera de interpretar la historia no es, como se decía páginas atrás, solo un proceso epistémico de reconstrucción del pasado, sino un proceso político que intencional y deliberadamente oculta el papel de grupos marginados de la historia, y del proceso social. De acuerdo con Benjamin en su tesis VII de los Apuntes sobre el concepto de historia, el historiador historicista entra en empatía con el vencedor de la historia, y con ello hace suyo el punto de vista de este y no el de la víctima, generando una continuidad entre los dominadores de ayer con los de hoy. Desafortunadamente, podemos constatar, Benjamin tiene toda la razón al respecto. Basta recordar, solo por citar un ejemplo reciente en Colombia, la manera como el único presidente negro de este país, Juan José Nieto Gil, fue deliberada y abiertamente sacado de los libros de historia oficial.
} 
distintos grupos marginados del camino de la "civilización”, aislándolos y, de paso, despolitizándolos: si no intervienen en el proceso de construcción de la historia es, básicamente, porque su papel no es determinante en la elaboración del entramado político. Porque no es mucho lo que pueden aportar desde su condición de inferioridad, ya que la historia está escrita por personalidades individuales sobresalientes.

Pero esta ausencia en la historia oficial de los grupos marginados, específicamente y para el caso de este texto de las comunidades indígenas y campesinas, se ampara, a su vez, en otro proceso adicional que potencia su marginalidad. Aislados del conocimiento, del proceso político y, por ende, del discurso histórico, las comunidades indígenas y campesinas fueron también concebidas como fundamentalmente incapaces de actuar y de organizarse por sí mismas. No solo no aparecen para la historia, sino que son los agentes pasivos de la misma: por su atraso e ignorancia necesitan de la mano salvadora del hombre blanco occidental que les dispone, desde sus criterios, una forma de organización externa. La jerarquización social, auspiciada por el principio de la propiedad privada, es también una forma de clasificación social con respecto al conocimiento. De hecho, si se revisa buena parte de la historia del pensamiento filosófico, este establece una radical separación entre el intelectual y el vulgo; entre el académico y la gente del común. Esta es una distinción recurrente en todas las ciencias humanas y sociales: los grupos considerados marginales al proceso histórico — racializados y diferenciados cualitativamente del ideal único-, no son capaces de conducción autónoma y por ello requieren ser intervenidos y estudiados por el científico social que sabe de ellos mucho más que ellos mismos. Una actitud tradicional del pensamiento moderno que, ya es hora de decirlo, expresa una posición de clase: los grupos que se han privilegiado históricamente son los agentes de la historia y el saber; protagonistas de los grandes acontecimientos reúnen las condiciones suficientes para alzarse con el poder político. Los otros, la chusma, los que vienen de atrás son, por mucho, testigos y espectadores de un proceso que se sucede sobre ellos $\mathrm{y}$, muchas veces, contra ellos. Pero no son agentes de la historia, ni del saber.

En concordancia con esta posición Yirmiyahu Yovel expresa, en su ingenioso estudio sobre Baruch Spinoza, que el filósofo de Ámsterdam recogía punto por punto la tradición moderna cuando consideraba que "la multitud es un grupo inferior, incapaz de salvarse verdaderamente y necesitado de alguna ilusión religiosa y en un estado inferior de conocimiento" (Yovel, 1995, p. 293). Esta concepción profundamente negativa de la "multitud", separada del conocimiento científico y filosófico, y abstraída de sus características específicas ${ }^{4}$, impera hoy en día y es la forma de clasificación de la mayoría

\footnotetext{
${ }^{4}$ Yovel señala que, a diferencia de Spinoza, Marx no tiene una concepción negativa del vulgo como grupo inferior. Todo lo contrario. "En Marx es la multitud misma, transformada en proletariado, la que redimirá al resto de la humanidad. Ella es sujeto y objeto de la emancipación racional y, para cumplir su papel, debe tener una conciencia de sí tan clara, lúcida y demistificada como la de cualquier filósofo; expresada acaso en términos más simples, pero con la ventaja añadida de estar inmersa en la vida real. Mientras que Spinoza había separado a la multitud del filósofo, Marx los une: el proletariado es la filosofía encarnada, el arma material y la corporización de la filosofía. En un movimiento quizá paradójico, pero también típico, Marx traspasa las cualidades tradicionales de los grupo esotéricos a su peculiar especie de multitud, socavando la categoría toda para dar forma al concepto de proletariado, vanguardia de la revolución y la redención" (Yovel, 1995, p. 293).
} 
de nuestras sociedades. Esa clasificación aprendida irreflexivamente de la "herencia" europea ha mantenido a las comunidades indígenas, campesinas y afrodescendientes en una condición marginal del proceso político. Pero esa caracterización ha empezado a cambiar progresivamente, y esos muchos y muchas que antes eran vistos como ignorantes, atrasados y salvajes, como menores de edad en sentido kantiano, son los protagonistas principales de un proceso de inclusión y apertura de la vida política y social en Bolivia. Esos muchos y muchas que antes eran silenciados y discriminados por su particularidad étnica y cultural, son los verdaderos agentes históricos del proceso de renovación política y social que ha vivido el hermano país. Desde la distancia, pero siempre atento a los cambios que se han venido sucediendo en su tierra natal, Saturnino expresaba entre nostálgico y feliz que las enseñanzas de los abuelos empiezan a escucharse de nuevo, y que la cultura de la Llajta ha entrado en escena para discutir la hegemonía imperante y amnésica del poder occidental. Es el resurgir de un pasado no olvidado y latente, de unas formas de organización política comunitaria que no habían sido consideradas como criterios legítimos, como tampoco eran valorados los saberes ancestrales ${ }^{5}$ y las lenguas indígenas.

El pensamiento occidental no puede ser pensado sin la colonización. Sin esa imposición estructural que ha dominado la mentalidad colectiva en los países latinoamericanos, configurando su identidad y sus estructuras sociales de espaldas a la alteridad. A esas otras visiones del mundo igualmente válidas y genuinas; a esos saberes milenarios de los diversos pueblos indígenas que se han relacionado armónicamente con la naturaleza, comprendiéndola como un sujeto vivo que también tiene derechos y con la cual se tiene una íntima relación existencial y de respeto. Esas enseñanzas de los abuelos de las que hablaba mi amigo han vuelto a renacer. Y aparecen en un momento histórico en el cual el sistema imperante se encuentra en crisis debido a sus profundas e insalvables contradicciones internas, y a una crisis profunda del Estado.

Esas voces renovadas se presentan como una alternativa real, en el escenario político estatal, para reivindicar una nueva forma de hacer política. O mejor no: no una nueva forma de hacer política, sino el inicio de la política tras casi dos siglos de dominación en nombre de la democracia. Porque no se puede hablar de política cuando solo existe un discurso dominante y una única estructura que se perpetúa indefinidamente; porque la muerte de la política es la negación de la diferencia del otro y la imposibilidad de reconocerlo como

\footnotetext{
${ }^{5}$ Un ejemplo que puede ponerse al respecto es el saber de los médicos Kallawaya. Estos sabios, médicos herbolarios ambulantes, conocen a la perfección la inmensa variedad de plantas, yerbas y animales existentes en el altiplano y sus distintas propiedades curativas. Más allá del criterio occidental de "efectividad" -porque además sí es efectiva esta práctica-, lo que quiero resaltar de la medicina Kallawaya es el componente ético de su labor: el médico viaja por las distintas regiones para atender en su casa al paciente, en una concepción de la enfermedad muy distinta a la occidental; vista como desequilibrio, como desarmonización, atiende con dedicación a cada persona y le procura un remedio natural para cada uno de sus males. Lo fundamental de su trabajo es el beneficio y la estabilidad del otro, y no su status social o los ingresos que pueda obtener de su saber. A pesar de estar reconocida por la UNESCO como patrimonio inmaterial de la humanidad, esta medicina sigue siendo mal vista por los profesionales de la ciencia médica, que no la dejan de considerar como una práctica exótica y llamativa, pero que no puede ser tomada en serio para el tratamiento de enfermedades (ide eso se ocupan los laboratorios farmacéuticos!). Además por el hecho de que el médico no ostenta un título que certifique su saber ancestral -que no es considerado legítimo, a la altura del saber occidental-, porque no está validado por una institución académica. Sin embargo, probada su efectividad y ante la posibilidad de patentar varios de estos saberes ancestrales para poderlos convertir en mercancía, muchas multinacionales farmacéuticas han puesto sus ojos en la medicina Kallawaya.
} 
interlocutor. Porque, en palabras de Jacques Rancière, no existe la política sin la irrupción del demos.

A fin de cuentas, la política comienza cuando el orden de dominación —que quiere presentarse como natural-, y la repartición de partes entre las porciones de la sociedad se ven interrumpidos por la aparición de una porción supernumeraria: el demos, que identifica la colección de los no contados en el seno de la comunidad. La igualdad, que es la condición no política de la política, no tiene efecto sino por el juego de esa parte litigiosa que constituye la comunidad política como comunidad de litigio. (Rancière, 1996, p.27.)

Es por esa irrupción de voces conjuntas y de las reclamaciones acumuladas por mucho tiempo frente a un sistema político unidimensional y hegemónico, que podemos afirmar que Bolivia viene viviendo, a pesar de todas las inmensas dificultades que ha costado andar este camino, un verdadero proceso de democratización. Y cuando digo democratización no me refiero al perfeccionamiento del sistema electoral, o a la ampliación del sufragio, sino al proceso de inclusión de otras formas de comprender y habitar el mundo a través de la movilización y el cuestionamiento al orden imperante, así también como de otras formas de organización política que suponen la puesta en escena de principios y valores sociales comunitarios que enfrentan la inercia política de un Estado basado en la destrucción de lo social. Para poder comprender el proceso boliviano es indispensable interpelar la concepción, también unidimensional, de la democracia. Porque esta no se reduce ni se limita al proceso de selección y alternación de gobernantes a través del voto, sino a una concepción mucho más amplia y diversa de la vida política en función de los principios de igualdad y autogobierno. A fin de cuentas

el voto [...] no es un acto político. Es un acto importante, pero es un acto estatal. Y entonces hay que diferenciar al acto político del acto estatal. Un acto estatal no es un verdadero momento de libertad. Es una especie de comprobación. En las elecciones lo que se hace es comprobar que las cosas siguen su curso. Y nosotros participamos en esta comprobación. (Badiou, 2000, p.1.)

Esa incursión de la diversidad expresada en las formaciones políticas de los diversos movimientos y organizaciones sociales, es el inicio en realidad de la política ya que esta supone, necesariamente, la correlación de fuerzas en disputa en el terreno público - y no solo por el manejo y la administración del Estado-. Ya que la política supone la relación entre varios sujetos y colectivos sociales en acción pública, implica la pluralidad y la diversidad de formas. Ante la dinámica unidimensional propuesta por la sociedad burguesa, excluyente de otras alternativas e impositiva de una concepción de la realidad, la incursión de una pluralidad de formas de vida y de alternativas de construcción política reanima aquel entorno de decisión, en el Estado, que había sido colonizado por una única interpretación de la vida social, y por unos intereses que, valga la pena decirlo, no toman en cuenta la distribución social de la riqueza. 
Esa nueva dinámica política implica entonces el proceso de empoderamiento y constitución de nuevas fuerzas sociales que trabajan entre sí y de manera conjunta, respondiendo a unas exigencias y a unas oportunidades históricas. Representa este nuevo proceso, en realidad, la apertura política y el cuestionamiento a un orden de poder inalterado que subordina toda la relación social y la hace dependiente de sus propias dinámicas. De un orden social que diseña la sociedad al tamaño de sus necesidades, utilizando diversas estrategias y mecanismos para fragmentarla, para despolitizarla e impedir su movilización.

La fragmentación de la sociedad es una estrategia del poder dominante y la sociedad fragmentada es la situación de gran parte de la población, que no sólo está alejada del poder, sino afectada en su propia capacidad de constituirse en mayoría con aspiraciones a lograr la hegemonía política [...] La sociedad fragmentada es la condición de nuestros pueblos, trabados en contradicciones superficiales, desorientados respecto a objetivos comunes, imposibilitados de asumir luchas colectivas. La fragmentación implica estrategias de desorientación. La sociedad fragmentada implica una mayoría — y a veces un pueblo entero- que ha perdido el rumbo de su propia causa nacional. Bajo esta perspectiva, afirmar que las verdaderas minorías discriminadas de nuestros pueblos latinoamericanos son las mayorías sociales, es una afirmación nuevamente rica para el análisis teórico y mucho más rica aún para la práctica política. (Binder, 1991, p.4.)

\section{Ayni llajta: el trabajo de la comunidad}

La vida política es, en palabras del profesor Luis Tapia, un pluriverso (citado por García, Prada, Tapia \& Camacho, 2010, p. 123). Pero este término, referido a la intersección de distintas formas de vida que divergen entre sí y convergen en el escenario público, es una característica que, en Bolivia, es determinante. Es su signo diferencial. Con esto quiere decir, en referencia a su país, que este es constitutivamente diverso y que no es posible reducir esa diversidad heterogénea a una única concepción homogénea. Es decir, en otras palabras, que el proceso político que vive Bolivia implica también la necesidad de reformular los conceptos y criterios políticos que empleamos para juzgar sociedades que, a diferencia de esta, no se caracterizan por una diversidad constitutiva tan marcada. Que para pensar a Bolivia no son suficientes las categorías del pensamiento occidental ya que este, tal cual ha sido definido en la sección anterior, se ha estructurado tomando como referencia un tipo de sociedad y de ser humano que no es el que caracteriza al país hermano. Y no solo porque en él no hay un solo tipo de ser humano, sino porque no se puede abarcar esa diversidad en unos términos que no han surgido de ella misma.

Esa diversidad constitutiva de Bolivia la hace un país "abigarrado ${ }^{6}$ y multisocietal" (Zabaleta, 2009). Un país que no tiene, por esa inmensa pluralidad de formas que coexisten,

\footnotetext{
${ }^{6}$ Este es un término acuñado por el sociólogo boliviano René Zabaleta Mercado (2009) para referirse a una formación social en la cual coexisten diferentes formas de vida social, diferentes formas de autoridad, cosmovisión, lenguaje, pero en donde no hay una que domine a las otras. Es una superposición de formas de vida que no se mezclan, que coexisten pero que no conviven necesariamente, formando un complejo entramado social en el cual la sociedad no se articula a un núcleo común.
} 
una articulación interna permanente. Y ya que hablamos de una diversidad societal muy compleja, no hay por ello mismo una única manera de comprender el poder, la autoridad y el sentido de la vida social; hay otras formas de vida política y de autoridad paralela al Estado. Por ese abigarramiento, por esa diversidad estructural, la forma de gobierno estatal coexiste con otras maneras de comprender el poder que no solo no reconocen necesariamente al Estado, sino que lo interpelan y no le permiten consolidarse como un factor de cohesión social. Pero esta diversidad no es simplemente una dificultad para el Estado: muestra sus limitaciones y su contingencia como forma histórica de poder. Lo cuestiona y pone al descubierto otra de sus estrategias de dominación: presentarse como la única forma válida de la política. Como la vida política misma. Esa reducción de la vida política al Estado se ha visto confrontada en Bolivia por el redescubrimiento de otras formas de organización no estatal que reclaman su derecho histórico de presentarse como alternativas políticas.

Pero el Estado no reduce ni capta toda la vida social; esta es mucho más amplia que la formación estatal. Esa es otra de las consecuencias de asumir sin cuestionamientos el modelo occidental: que este reduce la vida política a la participación en el Estado. Esa dificultad, que consiste primero en identificar la vida política con el Estado y, por ello, a la democracia como simple juego mecánico electoral para reproducir la inercia estatal, no ha permitido la irrupción de formas alternativas que cuestionen desde fuera esta reducción estructural de la política a la participación en la dinámica estatal. Esa simplificación de la vida política no solo tiene el efecto de fortalecer al Estado en detrimento de otras formas de organización y autogobierno por parte de las comunidades, sino en reproducir la idea, característica también de occidente, de que esa manifestación humana que es el poder político solo es válida cuando se ampara bajo una institución. Esa recurrente institucionalización de todas las formas de vida - académica, religiosa, política, cultural, familiar, la salud ${ }^{7}$, etc. - es una manera de separar el poder de su base social, diseñándolo como una estructura, como un mecanismo externo y artificial.

La institucionalización de la política es, al igual que cualquiera otra institucionalización, una manera de planificarla, estructurarla y controlarla con base en los intereses de aquellos que administran la institución. De cierta forma institucionalizar es presentar una faceta humana en su versión externa e instrumental. Un desdoble de lo humano suplantado tras su expresión artificial. Para el caso del Estado moderno, creación histórica de la sociedad burguesa para controlar el poder, consiste en poner a funcionar la política a partir de la mecánica propia del Estado que se desentiende de las dinámicas sociales que lo generan, dentro de una lógica interna y burocrática a la que debe responderse. Y esa lógica interna no es otra que la idea convencional de la democracia: forma institucional de salvaguardar el poder institucionalizado.

\footnotetext{
7 Por supuesto, en la sociedad occidental cada una de estas manifestaciones humanas vitales tiene su correspondiente institución que la controla, la regula y la disciplina: universidades y colegios, hospitales, manicomios, cárceles, iglesias, museos, bancos, etc. Instituciones que suplantan la formación social previa que las legitima como formas de control externas. Toda una contradicción del pensamiento occidental.
} 
Pero la idea occidental de la democracia no se refiere solamente a la manera de escoger el gobierno. Por encima de todo tiene que ver con una forma muy particular de idealizar el entorno social; de crear un modelo de sociedad habitado por individuos libres en apariencia y que compiten entre sí por sobresalir cada uno según sus capacidades, realizándose materialmente en el mercado. La idea de democracia se relaciona íntimamente con los procedimientos que son necesarios para mantener el orden y el tipo de vida propuesto por la sociedad burguesa. Y ese ideal, inserto en lo profundo de una sociedad "democrática", va ligado a la idea del progreso. Se ha querido asimilar la idea de la democracia a un tipo particular de procedimiento que legitima la institución estatal que subordina a su vez toda la vida política, y todo esto con el fin de salvaguardar el modo de vida burgués basado en el consumo - realización material en el mercado-. Después de tanto escuchar esta fórmula termina volviéndose una forma natural de conciencia, y así las personas tienden a asociar la democracia con la vida del consumo, y el espacio público reducido a la dinámica del mercado.

Por ello, podemos decir con Rancière que

Olvidada toda política, la palabra democracia se convierte entonces en el eufemismo que designa un sistema de dominación al que ya no se quiere llamar por su nombre, y a la vez en el nombre del sujeto diabólico que aparece en el lugar de ese nombre borrado: un sujeto heteróclito en el que se amalgaman el individuo que padece ese sistema de dominación y el que lo denuncia. Con sus rasgos combinados, la polémica dibuja el retrato-robot del hombre democrático: joven consumidor imbécil de pop-corn, de telerealidad, de safe sex, de seguridad social, de derecho a la diferencia y de ilusiones anticapitalistas o altermundialistas. (Rancière, 2007, p. 127)

En contravía de esta visión unilateral de la política y de la democracia, el proceso que vive Bolivia ha permitido la inclusión de espacios políticos que no eran considerados legítimos por no ser institucionales y electorales. El proceso de democratización en Bolivia ha implicado no solo el cuestionamiento a las viejas estructuras políticas de dominación sino, al mismo tiempo, al ideal de vida burgués que se ha pretendido eternizar y presentar como la única alternativa posible. Está apareciendo una nueva opción para el desarrollo del Estado, porque se hace válida esa visión del mundo que la soporta.

Esta afirmación de que el Estado no agota el escenario político ni la vida social nos permite afirmar, siguiendo de nuevo al profesor Tapia (2008a), que es ese subsuelo político, esas formas de vida previas que privilegian la comunidad y la relación constructiva con el territorio, quienes van a romper la hegemonía política, moral y discursiva dominante. Y es ese proceso de ruptura, de irrupción de formas alternativas de organización, el que posibilita, precisamente, el inicio de la política. Este proceso que está en curso ha implicado el reconocimiento y valoración de la identidad colectiva, comunitaria: un proceso de concienciación del lugar social que ocupa un colectivo de personas en el todo social al que llamamos Estado. Pero ese proceso de democratización implica la irrupción, el nacimiento de la política, entendida esta como confrontación en el escenario público de correlaciones de fuerza, de intereses políticos que luchan por la hegemonía en el ejercicio del poder. Sin la aparición de las grandes masas populares, la política se transforma en simple 
dominación, como dijimos antes. Es el surgimiento de la política que trata de rescatar el entorno social ${ }^{8}$, que implica no solo romper el monopolio histórico en el ejercicio del poder, sino su construcción "desde abajo", fruto de una forma alternativa de entender la vida y al ser humano.

Este subsuelo político, sujeto colectivo y diverso que protagoniza el proceso histórico de democratización en Bolivia, es el conjunto de espacios políticos que han sido generados por los movimientos sociales. Los movimientos sociales, señala el profesor Tapia (2008a), se diferencian de las organizaciones sociales por el hecho de que estas son corporativas, sin vocación ideológica, y no tienen un proyecto de cambio estructural; no solo son organizadas por el Estado (como los partidos políticos y los sindicatos, por ejemplo) y se someten a su lógica y dinámica, sino que responden a sus intereses. A diferencia de estas formas de acción colectiva articuladas por el Estado para su promoción y desarrollo interno, los movimientos sociales tienen una dinámica muy distinta que responde no a la naturaleza de la política estatal, sino a las demandas de cambio de diversos grupos que convergen por sus reclamos y, en ocasiones, por sus preceptos ideológicos. El movimiento social, para el caso boliviano, ha estado representado en una multiplicidad de espacios políticos autónomos pero relacionados (grupos indígenas, sindicatos obreros y campesinos, grupos de defensa contra la privatización de recursos públicos —como por ejemplo la Coordinadora del Agua en 2003-, grupos feministas, académicos, etc.), que se articulan entre sí en una acción colectiva que va más allá de los espacios propuestos por el Estado y la sociedad civil, cuestionándolos estructuralmente a través de la conformación de un bloque de poder.

Este trabajo mancomunado, este crisol de diversas voces que convergen en sus cuestionamientos y exigencias por el reconocimiento de sus formas de vida ante el Estado, es una acción política que trasciende sus núcleos de origen y se va expandiendo hacia otros espacios sociales, mostrando que el problema no es particular y no afecta solo a un grupo específico, sino al conjunto de la sociedad. A manera de ejemplo se podría decir que, frente a las protestas por la privatización y explotación desmedida de recursos naturales, convergen no solamente comunidades indígenas y campesinas, sino grupos ecologistas que asumen como propio el reclamo y se unen ampliando el espectro de demandas y exigencias contra el Estado, formando un nuevo discurso social que permite, de paso, un conocimiento más amplio sobre la sociedad misma.

Los distintos ciclos históricos de movilización social en Bolivia han permitido descubrir la importancia y la necesidad de salvaguardar principios comunitarios de organización como el criterio decisivo para interpelar al Estado desde afuera. De otra manera, en los términos y terrenos que este propone, solo se estaría contribuyendo a su reproducción. Pero la esencia de este subsuelo político es que rescata una forma de vida e identidad comunitaria. Formas de organización que privilegian a la comunidad por sobre el interés individual. Empleo la palabra "comunitaria" en el sentido de identificación intersubjetiva: cuando la persona individual es capaz de reconocer que sus propios planes y proyectos de vida se identifican

\footnotetext{
${ }^{8}$ Lo social entendido también como respeto a la naturaleza y valoración de la mirada indígena del mundo. Como proceso de descolonización sistemática.
} 
plenamente con los planes y proyectos del grupo al que pertenece. Y este proceso transcurre en un espacio concreto, y en momentos específicos. No es una abstracción, sino un modo cotidiano de ser con los otros. Esa dinámica, completamente opuesta al pensamiento moderno individualizante, y a la fragmentada sociedad burguesa, permite el rescate del principio del bien común, de la realización individual en, y por la comunidad.

Esta inclusión del elemento comunitario, del elemento social en el discurso político, trae a escena un modo de comprender al ser humano que se opone a aquel que justifica la sociedad burguesa. Es la posibilidad de romper la monotonía, por todos lados difundida, en la que a eso a lo que se llama "social" no es otra cosa diferente que el espacio del mercado: paso obligado pero no deseado para la satisfacción de las necesidades, en el cual uno entra a relacionarse con los demás viéndolos como potenciales competidores. En esta fragmentación del núcleo social, al reducirlo a mercado, es en lo que consiste la contradicción fundamental de la sociedad burguesa. Su crisis se basa en reducir a la vida social, entendida como un ámbito comunitario de construcción multilateral y de diversas voces que logran acuerdos racionales, a las relaciones de mercado. La fragmentación social de la que se alimenta el sistema neoliberal supone que los individuos son una especie de mónadas aisladas entre sí, que compiten constantemente por alcanzar sus logros y fines personales. Un espacio de control social que impide el ascenso del "nosotros", al fortalecer el "yo". Y en esa lucha por la propiedad privada, esencia misma de la sociedad burguesa, el entorno social se ve inevitablemente fragmentado.

La dominación se basa en la ignorancia y en la socialización de patrones intelectuales que incorporan la subordinación, la jerarquía y la subalternidad en la constitución de los sujetos. La dominación se levanta sobre un proceso de desorganización de las condiciones sociales, políticas y culturales en las cuales los diversos sujetos sociales podrían conocerse a sí mismos a través de la relación con otros sujetos en el contexto de los procesos nacionales e internacionales. Dominar implica desorganizar las condiciones de reconocimiento entre sujetos sociales, especialmente en el mundo de los trabajadores. La desorganización produce desconocimiento, de sí mismo como sujeto individual y colectivo, de los otros sujetos, del país y del mundo. La estrategia de dominación neoliberal se propuso desorganizar a los trabajadores y otros núcleos sociales para poder imponer sus patrones de apropiación del trabajo y control de las poblaciones trabajadoras. (Tapia, 2008b, p. 104)

A diferencia de esta fragmentación inherente que propone el neoliberalismo, los movimientos sociales en Bolivia han propendido a fortalecer el núcleo común. Con la conciencia siempre abierta al reconocimiento de las diferencias, se han logrado salvaguardar los principios comunitarios que soportan todo este proceso. Esas formas de organización colectiva, herederas de espacios de participación y construcción política ancestral, replican formas de socialización que tienen asiento en prácticas campesinas e indígenas. Esta autodeterminación de las propias comunidades fuera del espacio político estatal, es una característica decisiva que hace del proceso boliviano el resultado de fuerzas que se encuentran latentes al proceso institucional. Es más, son formas de organización comunitaria, dinámicas políticas no estatales que rompen con esa dicotomía cerrada y 
excluyente, mencionada páginas atrás, que pretende establecer una relación tautológica entre Estado y política.

Este antecedente, construido históricamente y a lo largo de las diversas fases de movilización social y campesina, permite determinar que el proceso de democratización que ahora vive Bolivia no es solo resultado de las exigencias y reclamos populares ante el Estado, esto es, de procesos de movilización coyuntural que exige del establecimiento político una respuesta efectiva ante determinada circunstancia específica, sino la manifestación abierta y declarada de otra manera de hacer política, esto es, de otra forma de alcanzar los objetivos de un grupo a través de una dinámica de empoderamiento. Pero esas fuerzas políticas, esas formas de organización y conciencia colectiva que llevan adelante esas demandas ante el Estado no son partidos políticos sino fuerzas sindicales agrupadas con otros actores sociales. El papel protagónico que ha jugado la Central Obrera Boliviana — punto de unión de los sindicatos y organizaciones comunitarias_-, es una manifestación de una práctica organizativa al margen del Estado que lo confronta y le hace claros sus límites y alcances. Un buen ejemplo de cómo el subsuelo político, sin embargo diverso entre sí, se condensa en una manifestación que responde en nombre del principio del bien común y se consolida como interlocutor político válido.

El caso del MAS, partido político creado para competir en la dinámica electoral pero como vanguardia y en nombre de ese proceso previo de movilización social, también es representativo: fue resultado de la convergencia de diversos procesos de movilización y de distintos sectores sociales que lo conformaron como el instrumento político del proceso. Pero solo como eso, como instrumento político, y no como finalidad misma de la política. Sin embargo, los movimientos sociales no pueden ser asimilados por el partido político. Son dos instancias diferentes. Como recuerda Boaventura de Sousa Santos, la función histórica de los movimientos sociales es abrir la agenda política, luchando por mantener una discusión permanente sobre unos objetivos que antes eran diseñados por los intereses de los partidos políticos, que naturalizaban los problemas sociales así también como las soluciones posibles. De la misma manera, insiste el teórico portugués, "los movimientos sociales no son ni van a ser gobierno; ese no es su papel. Siempre serán la enorme fuerza que ayuda a fortalecer las condiciones del proceso de gobierno" (De Sousa Santos, 2008, p. 136). La naturaleza de los movimientos es estar movilizados para presionar al gobierno y mantener equilibrada la correlación de fuerzas, pero sin desmovilizarse porque su esencia es la movilización, el cuestionamiento permanente. Es una forma de presionar "desde abajo" en tanto son una fuerza política viva y activa. Fuerza renovadora y creativa.

Los movimientos sociales bolivianos han heredado, de procesos históricos de rebeldía y organización, nuevos criterios para la acción política. Criterios que son determinantes para establecer una comparación frente al poder que están interpelando. Por ejemplo, se soportan sobre ideas del poder y del liderazgo, muy distintas a las que propone la razón occidental. Primero que todo porque el poder no implica, ni una institución, ni una voluntad individual que subordine a los demás. No es, digámoslo así, una cualidad distintiva que limita y separa; no es un estatus social que crea una brecha entre quien detenta el poder y quien se somete a él, pues no tiene que ver con la noción de jerarquía. Todo lo contrario: el 
liderazgo se soporta en la idea tradicional de respeto a la decisión de la comunidad. El líder no es el que impone su criterio, sino el que responde a la voluntad general: se manda obedeciendo. Mientras que el liderazgo occidental apela a la superior emanada del cargo e implica separación con la base y jerarquización —en donde el poder implica dominación, disciplina-, el punto de vista indígena coloca su atención en el proceso comunitario que soporta y justifica la delegación participativa del líder: "no el que quiere ser saludado porque es presidente, sino el que debe saludar a las bases porque es dirigente" (De Sousa Santos, 2008, p. 136). Es al contrario: nadie lo debe saludar, él debe saludar porque manda. En esta concepción el liderazgo no se expresa como estatus, sino como servicio, y la base social no es una audiencia depositaria de las decisiones de una voluntad individual, sino quien establece el compromiso de servicio y obediencia a la que se debe responder, porque prima el proceso de la voluntad general por sobre la particular: no es una "dignidad" superior, sino una obligación de servicio. Un criterio ético de relación con los otros.

Así pues, la presencia de esa nueva cultura política abanderada en formas de vida comunitaria cuestiona los fundamentos del poder occidental. Como se ha dicho ya, la política ni empieza con su forma estatal, ni se agota en ella. El desconocimiento que la razón instrumental occidental ha hecho de otras formas de vida y organización lleva a ese proceso de imposición colonial de una forma de poder y de autoridad que se implementa sobre espacios ancestrales de vida con los cuales no es empático, con los cuales tiene una diferencia cualitativa profunda. Buena parte de los cambios institucionales que se han generado en Bolivia, siguiendo la tesis del profesor Tapia, han sido gestados y promovidos desde la configuración de otros espacios políticos que estaban fuera de los espacios tradicionales configurados por el Estado.

Es decir, hay un tercer componente, relacionado con la presencia de otras culturas políticas, que aparecen a través de sujetos comunitarios, de manera combinada en el seno de los sindicatos, y que en el momento de la transición todavía se canalizan hacia el apoyo electoral a un frente bastante amplio de izquierdas. (Tapia, 2008, p. 13)

Pero, precisamente para evitar el estancamiento y la inercia característica de la formación estatal frente a la cual se quiere trazar un límite, es indispensable la acción permanente. La movilización social no puede estancarse siquiera cuando se alcanza uno de los objetivos buscados: llegar al gobierno. Este solo fue el inicio de un nuevo momento en el proceso de emancipación que vive Bolivia. Pero no se pueden confundir los medios con los fines, y viceversa.

Permítaseme al respecto una breve comparación: de la misma manera que ocurre en las relaciones interpersonales en el plano sentimental en donde la pareja vive, durante el noviazgo, un proceso de enamoramiento y empatía que los lleva a la decisión de llegar al matrimonio, este no es simplemente la realización del proceso previo del noviazgo, sino el inicio de otra vida diferente en donde las princesas y los príncipes se convierten en personas reales a través de la convivencia. El matrimonio no es el culmen de la relación interpersonal, su máxima realización; es solo el inicio de un proceso que, si bien se gestó con dificultades o no- durante el momento previo del noviazgo, inaugura una nueva fase donde la relación cambia de sentido y los objetivos que se persiguen, las dinámicas cotidianas, el lenguaje y las decisiones que deben tomarse son otras. Así también ocurre en 
el plano de la relación con el poder: no se agota con la llegada al poder, a través del rito de legitimación que en este caso es la dinámica electoral, sino que allí empieza, en realidad, el proceso de concreción de todos los esfuerzos previos. Pero es un proceso diferente que, como se ha insistido, debe ponderar todas las variables incluidas en el hecho de estar a la cabeza de una organización política que no es, de suyo, similar a las formas de organización y a los sujetos y espacios políticos previos que la permitieron. Requiere de una constante revisión y de la conciencia siempre clara de que no se puede separar de la base que lo permitió. Esta debe seguir movilizada, amparando y cuestionando el proceder del gobierno cuando sea necesario. Porque el proceso boliviano tampoco se agota con la llegada del Evo al poder. Esa es, si se permite la afirmación, la consumación del proceso previo que culmina con la toma del poder. Pero de allí en adelante es a otro precio. Creer que con llegar al poder se ha logrado el objetivo, es tanto como pensar que todo el matrimonio será como el momento eufórico de la ceremonia nupcial — io de la luna de miel!- . Este es el inicio de otra fase, complementaria con la anterior y determinada por el proceso anterior, pero otra fase. A fin de cuentas, si se quiere generar un verdadero proceso de descolonización y de empoderamiento de las comunidades previamente olvidadas, no se puede perder de vista que el poder implica, en las estructuras tradicionales comunitarias, una absoluta fidelidad y obediencia hacia la comunidad quien lo detenta, en último término. Esa ruptura y desarticulación entre el gobernante y los gobernados, propia de la dinámica estatal en su forma de selección electoral, no puede ser replicada para el caso de un gobierno que se jacta, al menos verbalmente, de responder a las exigencias de un pueblo que se ve reflejado en su gobernante por primera vez en la historia.

Porque de la misma manera que hemos dicho que el Estado moderno se ha ido configurando históricamente respondiendo a unos intereses políticos, antropológicos y económicos específicos, también debemos admitir, usando el mismo criterio, que el proceso que se adelanta en Bolivia debe ir aprendiendo y desaprendiendo sobre la marcha y que no ha llegado a la plenitud de su desarrollo. Que es un proceso que tiene que tener, a cada paso, conciencia de su actuar histórico. El hecho de que responda a dinámicas previas de organización social no es garantía de su completa y correcta realización en el escenario estatal en el cual entra a jugar. Y no solo por el hecho de adaptarse a esquemas institucionales, burocráticos y de poder que difieren completamente de la base comunitaria de la que deviene, sino por el hecho de que, por primera vez en la historia, esas diversas formas de pensar, sentir y comprender al otro llegan al poder y se encuentran con la tarea de dirigir la totalidad de la vida en el país. Porque además hay que anotar que existen diferencias sustanciales en el hecho de hablar desde la otra orilla del poder establecido, confrontándolo y discutiendo permanentemente desde la oposición, al hecho de ocupar el lugar protagónico que caracteriza la captación del gobierno. Este hecho de estar abanderando, si se me permite el término, el proceso general de organización social supone no solo una perspectiva diferente de la realidad social, esta vez desde el poder, sino una responsabilidad mayor de ser coherente con los procesos, organizaciones y movilizaciones que permitieron la toma del poder.

Es esa necesidad de responder a la base, y de ser coherente con los principios y proyectos que permitieron al MAS alcanzar el gobierno la tarea más difícil y la que, como también 
señala el profesor Tapia, es tal vez la mayor dificultad del actual gobierno boliviano. Y lo es no solo por la aplicación de políticas neoliberales que atentan contra las comunidades indígenas y campesinas. Es mucho más grave que esto. Es desandar lo andado por asimilar las mismas dinámicas y prácticas de poder contra las cuales el proceso de movilización levantó su voz enérgica; su mayor dificultad en el ejercicio del poder consiste, precisamente, en asumir el poder en el mismo sentido de las tradicionales oligarquías y grupos de poder que excluían las formas comunitarias del poder. Por no entender que, así como el proceso general de movilización, el poder y el liderazgo también son formas activas que se construyen comunitariamente y en permanente diálogo con la base. No son, en ningún sentido, una cualidad específica de uno u otro grupo político.

La clave para enfrentar la dominación no es la organización en general sino la autoorganización. Las estrategias de dominación organizan a la gente en posiciones de subordinación, de recepción del mando, de una autoridad jerarquizada más allá y fuera de la colectividad gobernada. La organización produce poder, y a veces eficacia. La autoorganización produce poder y libertad. La organización nos constituye en sujetos a través de una cadena de posiciones que articulan las estructuras y relaciones de poder. La autoorganización nos constituye y reconstituye como sujetos en fluidez. La autoorganización no nos estabiliza en las relaciones de poder, sino que es una apertura a nosotros mismos y en relación al conjunto de relaciones sociales que nos condicionan y que afectamos a partir de la propia iniciativa. (Tapia, 2008b, p. 109)

Porque puede ser que el gobierno, por diversas razones políticas o cediendo a los intereses económicos neoliberales, haya olvidado los horizontes iniciales que lo llevaron al poder del Estado y los proyectos pactados previamente - como también en el matrimonio se olvidan, a veces, las promesas del noviazgo que lo hicieron posible - , pero a la comunidad no se le olvidan. Eso es seguro. Muchas de las políticas del MAS van en contra de las comunidades indígenas, y promueven una desarticulación del proceso movilizador comunitario; una ruptura de la forma política primordial que lo sustenta. Pero el bloque político que soporta al gobierno y que lo legitima, no deja de juzgar las actuaciones del ejecutivo con base en la coherencia que este tenga, o no, en su accionar respecto de las promesas que lo llevaron al palacio presidencial.

El problema actualmente parece ser que el divorcio se está gestando gracias al bloqueo del subsuelo político propiciado por el gobierno: el cuestionamiento, judicialización y entorpecimiento de los espacios de deliberación política fuera del espacio estatal. Esa monopolización del discurso político, y el consecuente juicio a las diversas voces que lo interpelan, puede ser el punto de quiebre definitivo que haga perder al gobierno la oportunidad histórica que siempre buscó. Pero no representa el fin del proceso de movilización que se ha echado a andar y que no se va a detener si es consecuente consigo mismo. A fin de cuentas hemos dicho que la política no se agota en ese juego electoral. Que es algo más, y que el descubrimiento de ese espacio es el aporte novedoso de Bolivia a la historia reciente de América Latina: el nuevo proceso de concienciación ciudadana sobre sus capacidades y sobre el papel que juega en la dinámica política; la maduración de la 
conciencia sobre lo que significa vivir en democracia y, por ende, una nueva conciencia de lo que es el Estado, de su finalidad y propósitos.

\section{La construcción ética del sentido social: el retorno de la Pachamama}

Además de la importancia definitiva que han tenido los movimientos sociales en el proceso de transformación de la sociedad boliviana, proceso que ha implicado subvertir el orden político imperante al posicionar otras visiones políticas comunitarias, hay otro elemento que quiero resaltar antes de finalizar este ejercicio. Ese subsuelo político trae consigo otra de sus formas distintivas: la introducción de unos principios éticos que van a fundamentar el discurso político. Es la idea de una comunidad humana amparada en el ideal del sumak kawsay, del buen vivir que implica el rescate de la vida comunitaria e intersubjetiva, en íntima comunión con el medio ambiente. Esa es la herencia de los abuelos de la que con tanto respeto y afecto me hablaba Saturnino. Cosmovisión que ahora se recupera y entra en escena para sacudirse del yugo impuesto por el discurso reduccionista y homogeneizante de la cultura occidental. Imagen del mundo y del hombre que reclama su derecho histórico para ser tenida en cuenta.

Hemos dicho hasta el momento que la democracia implica el proceso de búsqueda de igualdad y de reconocimiento a las diferencias constitutivas de la nación boliviana. Tiene que ver con un proceso de ampliación de la democracia - que hemos llamado democratización - que implica la participación y el reconocimiento del subsuelo político; una ampliación del terreno social y una entrada al ámbito político de las diversas subjetividades y formas de organización intersubjetiva que han sido puestas al margen en Bolivia y en otros muchos países de América Latina. Pero consiste, también, en darles la palabra a las personas más humildes y, antes que esa odiosa actitud que a veces asumen algunos de aquellos que se hacen llamar científicos sociales, que los estudian como objetos de su investigación, se debe poder aprender a escuchar. Ese es el interesante ejercicio que se consigna en el libro Bolivia: 25 años construyendo la democracia: visiones sobre el proceso democrático en Bolivia 1982-2007, publicado por la Vicepresidencia de la República.

En este texto, después de las necesarias y sensatas intervenciones de destacados y comprometidos intelectuales, se hizo un ejercicio de participación abierto en el que diversas personas de la comunidad intervenían expresando su punto de vista sobre el proceso que ha vivido su país. Esa lectura fue más que interesante, pues me hizo reconocer la importancia de entender el proceso en las mismas palabras de las personas que han luchado por él. Que si bien desde la academia tratamos de interpretar y de colocar conceptos para explicar realidades ajenas a nuestra propia vida cotidiana, es importante rescatar las propias voces de aquellos que, para el lenguaje, no habían sido tomados en cuenta como interlocutores válidos, como hablantes. No puedo acá reconstruir e interpretar todas las diversas intervenciones, ni sintetizar en categorías de análisis la pluralidad de expresiones que el libro recoge. Hacerlo sería incurrir en aquello mismo que estoy criticando. Antes bien, mi intención es resaltar un aspecto de suma importancia: la inclusión de principios éticos y la 
conciencia de que, sin ellos, el proceso boliviano no tiene futuro. Además, y esto también es muy importante, el hecho de que ha empezado a surgir una idea del futuro; una renovada esperanza en una vida mejor.

Pondré algunos ejemplos que me parecen representativos. Frente a la pregunta de los logros alcanzados hasta el momento, una mujer ${ }^{9}$ responde:

Entonces yo creo que en estos 25 años de democracia el valor básico para todos es haber sabido madurar. Ver los errores que uno tiene es algo importante de conocer o reevaluar. El pueblo se ha dado cuenta que esa clase de democracia estaba fingiendo, que solamente era de una oligarquía, que no sentía por el trabajo, se servía del pueblo como escalera. El pueblo no tenía libertad de opinión, ni de voz, ni de voto. (Tapia, 2008, p. 125)

Como se mencionó hace un momento, la idea de democracia se acompaña de un proceso de concienciación. Es un proceso de concienciación de sí mismo y del entorno social. Pero también tiene que ver con un ideal, con la aspiración de lo que se quisiera que fuera la sociedad boliviana.

Y al respecto la intervención de otra mujer es más que clara:

Imaginamos un país donde nazcan niños gordos, rozagantes, trabajando su tierra así como también una familia con planificación y con orden. Hemos considerado importante todo esto porque la familia es, tal vez, el primer punto donde se educa el concepto de democracia y es, tal vez, donde más estamos fallando. (Tapia, 2008, p. 118)

¿Pueden ser más claras estas palabras? No. La idea que tienen las personas del proceso que vive su país implica necesariamente pensar la posibilidad de una nueva forma de vida, de una vida buena en donde el fundamento de la misma es la propia vida: poder vivir tranquilos, trabajando su tierra y donde los niños nazcan sanos en un ambiente de amor y respeto. Una imagen del futuro con base en una idea de la familia cimentada en el amor, la salud, la buena alimentación. Se percibe la familia como el primer punto desde el cual se educa en el concepto de democracia, lo que implica que esta se asocia con un ámbito de reclamo intersubjetivo, comunitario. Hay muchas más intervenciones en el mismo sentido, pero, más allá de un listado exhaustivo, pretendo decir que ya existe un horizonte, un proyecto que orienta las acciones populares.

Pero esos principios éticos se construyen colectivamente. No son un a priori, o una idealización abstracta: nacen de la interacción igualitaria entre las personas.

La igualdad es algo muy importante, así como la equidad de género, ya que en este país y en este contexto suramericano abunda la desigualdad: el hombre se cree superior a la mujer, el rico se cree superior al pobre, el citadino se cree superior al campesino, al indígena, etc. (Tapia, 2008, p.118)

\footnotetext{
${ }^{9}$ En el libro no aparecen los nombres propios de las personas que intervienen. Solamente están reseñadas como "mujer", o como "hombre".
} 
Esta igualdad, que reconoce la diversidad, converge también en el rescate de los principios ancestrales de los abuelos que ven en la naturaleza una extensión de la propia vida: el ama qhilla, ama llulla, ama suwa, elementos que están presentes en ese despertar después de muchos años de explotación sistemática entre los propios seres humanos, y también de los recursos naturales. Tal vez esos principios éticos, motor fundamental del proceso boliviano, puedan ser expresados mejor a través de un símbolo: la Wiphala es, como me explicó Saturnino, la bandera que flamea, la bandera ondeante, en movimiento, que refleja el colorido del arco iris y representa, con sus distintos tonos, la integración, la unidad en la diversidad de los diversos pueblos que se identifican con un color que no es independiente de los demás, ni significa separación, sino integración en unidad. La Wiphala es el símbolo del proceso de democratización, porque representa el ideal de una comunidad humana que se une desde su diferencia, desde la pluralidad de formas de vida que convergen en un propósito común. Es la diversidad, pero la integración al mismo tiempo.

\section{Conclusiones}

Para terminar quiero llamar la atención sobre el hecho de que eso que las personas llaman en el conversatorio "valores democráticos" tiene el tono de una lucha, de una conquista. De nuevo, la idea de la democracia como una actividad, como un proceso que se instaura colectivamente y desde las masas populares. El principal valor de la democracia en Bolivia es que ha sido conquistada, como forma de vida participativa e igualitaria - en el sentido, al menos, de la inclusión de diversas formas de vida y expresión antes menospreciadas-. No es un "catálogo de derechos", sino algo que se construye colectivamente. No hay un modelo, no hay un solo sistema, más bien la pluralidad de formas de vida y cultura de los pueblos, lo que hace también que haya una pluralidad de democracias.

Las distintas personas hacen un especial énfasis en lo colectivo, en el proceso de interacción cotidiana y participativa en el que intervienen los miembros de una determinada comunidad o asociación. Pero, sobre todo, en la dimensión ética que implica la nueva concepción de la vida sociopolítica. Mientras que la característica del pensamiento liberal fue desvincular - al menos formalmente- cualquier discurso ético en el marco de la política, liberando con esto las insaciables fuerzas del capitalismo y del Estado, la valoración del proceso emancipatorio boliviano pone, en palabras de las personas más humildes, un componente ético ineludible e indispensable en toda dinámica que pueda considerarse democrática: es la introducción de principios éticos reguladores, de principios normativos sobre los cuales se cimenta la relación social. Por ello, en muchas de las intervenciones del ejercicio mencionado es recurrente asociar la democracia con ideas como respeto, solidaridad, empatía, compromiso social, búsqueda del bien común, entre otras. Esta nueva manera de concebir el proceso de organización social, caracterizado por fundamentarse desde una visión del mundo mucho más amplia y diversa que la propuesta por el liberalismo, es de suyo una ganancia impresionante que, más allá de legislaciones o códigos formales en el derecho positivo, es una forma de regular la vida desde el principio de respeto y convivencia.

Las palabras de tantos bolivianos y tantas bolivianas, respetuosamente consignadas en el libro, no hacen énfasis en la formalización de derechos y la legalización de procedimientos, 
sino en comprender que todo el fundamento de lo político tiene su asiento en una eticidad que deviene de las formas de vida concretas y específicas de los pueblos que componen el país. Y no hablo de la eticidad hegeliana, manifestación espacio-temporal de la dinámica del espíritu absoluto, sino de la posibilidad de reconocer como válidas las formas de relación intersubjetiva y de construcción de un núcleo común de relacionamiento presente en las comunidades indígenas. Estas formas de vida concretas que privilegian el papel de la comunidad y anteponen los valores colectivos y ancestrales, no solo son dignas de ser aprendidas y tomadas como referencia, sino que son el punto de partida sin el cual la nueva concepción política carecería de sentido. En el caso boliviano no nos referimos a la instrumentación del aparato burocrático estatal, o a la política entendida como dinámica de relaciones de clase, sino a la presencia de una nueva forma de comprender al hombre y a la mujer, en una perspectiva de construcción conjunta en espacios culturales y sociales que implican una relación vinculante con el medio ambiente.

Es una forma de subvertir el orden político. En palabras de las personas, la democracia implica respeto mutuo no solo entre las formaciones culturales identitarias de las diversas comunidades y formas de organización, sino a las mayorías que históricamente han sido silenciadas y obviadas en el proceso de construcción del entorno político. Ese advenimiento de los valores éticos que van a regular el trato entre personas en un entorno social que se construye colectivamente con base en el respeto por las diferencias, más allá de la ruptura y fragmentación, de la competencia propia que generan los entornos capitalistas, se convierte en una alternativa de convivencia y reconocimiento recíproco que es, por encima de todo, un rescate del entorno social comunitario destruido tras el proceso de imposición neoliberal. Este proceso, es bien sabido, funciona con base en la desarticulación de las relaciones sociales y de asimilarlas, sin más, a las relaciones de mercado. El surgimiento de estas nuevas voces, en diversos dialectos y formas narrativas, recupera el ámbito normativo de las relaciones sociales, del territorio y del trato ético que debe mediar en toda relación humana que tenga como objetivo la convivencia y no la mera coexistencia de mónadas aisladas que compiten entre sí.

Entonces, una valiosa enseñanza acerca de un renovado humanismo es lo que se observa tras el proceso democratizador en Bolivia: tenemos un buen ejemplo que nos demuestra cómo deberían ser las relaciones sociales que configuran la política, y no solo cómo son, fácticamente, tras el disciplinamiento cultural burgués. Esperemos que esa renovada y fortalecida conciencia social continúe su proceso de movilización, y que el ideal de la Wiphala inspirado en la Pachamama siga presente en todos y todas aquellas que asumen este proceso como un compromiso de vida. 


\section{Referencias}

Badiou, A. (2000). Movimiento social y representación política. Revista Acontecimiento, (19-20).

Binder, A. (1991). La sociedad fragmentada. Caracas. Recuperado de www.chubut.gov.ar/portal/wp.../wp.../7/.../LA-SOCIEDAD-FRAGMENTADA.doc

Boron, A. (2000). Tras el búho de Minerva. Mercado contra democracia en el capitalismo de fin de siglo. Buenos Aires: CLACSO.

Braudel, F. (1993). Las civilizaciones actuales. Estudio de historia económica y social. Madrid: Technos.

De Sousa Santos, B. (2008). Pensar el Estado y la sociedad: desafíos actuales. La Paz: Coedición CLACSO, Muela del Diablo, Comuna.

García, A., Prada, R., Tapia, L. \& Camacho, O. V. (2010). El Estado: campo de lucha. La Paz: Coedición CLACSO, Muela del Diablo, Comuna.

Lander, E. (2000). Ciencias sociales: saberes coloniales y eurocéntrico. En E. Lander (comp.). La colonialidad del saber: eurocentrismo y ciencias sociales. Perspectivas Latinoamericanas (p. 11-40). Buenos Aires: CLACSO.

Memmi, A. (1966). Retrato del colonizado, precedido por el retrato del colonizador. Prólogo de Jean Paul Sartre. Buenos Aires: Ediciones de La Flor.

Quijano, A. (2000). Colonialidad del poder, eurocentrismo y América Latina. En E. Lander (comp.) La colonialidad del saber: eurocentrismo y ciencias sociales. Perspectivas latinoamericanas. (págs. consultadas). Buenos Aires: CLACSO.

Rancière, J. (1996). El desacuerdo. Política y filosofía. Buenos Aires: Nueva Visión.

Rancière, J. (2007). El odio a la democracia. Buenos Aires: Amorrortu.

Tapia, L. (2008). Bolivia, 25 años construyendo la democracia. Visiones sobre el proceso democrático en Bolivia 1982-2007. La Paz, Bolivia: Vicepresidencia de la República, CIDES/UMSA, FBDM, FES-ILDIS, PADEP/GTZ, Idea Internacional, PNUD-Bolivia.

Tapia, L. (2008a). Política Salvaje. CLACSO Coediciones. La Paz: CLACSO, Muela del Diablo, Comuna. 
Tapia, L. (2008b). La reforma del sentido común en la dominación neoliberal y en la constitución de nuevos bloques históricos nacional-populares. En A. E. Ceceña (coord.) De los saberes de la emancipación y de la dominación (p.101-113). Buenos Aires: Consejo Latinoamericano de Ciencias Sociales CLACSO.

Yovel, Y. (1995). Spinoza, el marrano de la razón. Barcelona: Anaya \& Mario Muchnik.

Zavaleta, R. (2009). La autodeterminación de las masas. En L. Tapia (comp.). Bogotá: CLACSO-Siglo del Hombre.

\section{Derechos de autor}

Los derechos de autor de este artículo son retenidos por los autores, con los derechos de primera publicación otorgados a la revista. Este es un artículo de acceso abierto distribuido bajo los términos y condiciones de la licencia Creative Commons: Reconocimiento-NoComercial-CompartirIgual 4.0 Internacional 